Volume 8, No.5, September - October 2019

International Journal of Advanced Trends in Computer Science and Engineering

Available Online at http://www.warse.org/IJATCSE/static/pdf/file/ijatcse97852019.pdf

https://doi.org/10.30534/ijatcse/2019/97852019

\title{
A Career Track Recommender System for Senior High School Students using Fuzzy Logic
}

\author{
Marvee Cheska B. Natividad ${ }^{1}$, Bobby D. Gerardo ${ }^{2}$, Ruji P. Medina ${ }^{3}$ \\ ${ }^{1}$ Technological Institute of the Philippines-Quezon City, Philippines, marveecheska@gmail.com \\ ${ }^{2}$ West Visayas State University, Iloilo City, Philippines, bobby.gerardo@ gmail.com \\ ${ }^{3}$ Technological Institute of the Philippines-Quezon City, Philippines, ruji.medina@tip.edu.ph
}

\begin{abstract}
Rule-based algorithms are mostly used in recommender systems but still, cannot address the issue of uncertainty in decision making particularly to senior high school students in choosing the right career track because of numerous influential factors that may affect their decisions. That is why a career track recommender system using fuzzy logic has been developed to address this issue. In this paper, the significant factors that is most influential to the decision of the students as best attributes were determined using feature selection filtering techniques and used as crisp inputs. The result shows that the developed fuzzy model performs a high predictive accuracy based on the computed mean absolute error (MAE) and root-mean-square error (RMSE) scores which decreases from the training, to the validation and test sets. The recommendation returns the best possible result based on the computed normalized discounted cumulative gain (nDCG) which is 0.948 from the desired to the actual preference of students which is almost near to 1.0. With these, the developed recommender system is highly recommended as perceived by the users in terms of usability, maintainability and portability.
\end{abstract}

Key words : Career track, feature selection, fuzzy logic, recommender system

\section{INTRODUCTION}

The $\mathrm{K}$ to 12 program of Department of Education in the Philippines as pursuant to the commitment of the country to realize one of the goals of Education for All 2015 (EFA 2015), aims to prepare senior high school graduates for better educational opportunities and to be more competitive workers through earned national certificates [1]. As such, it offers tracks for the students to choose from based on what they are good at, or which course they are interested in to take for college [2].

Though career plans are incorporated in the $\mathrm{K}$ to 12 curriculum, the collaborative effort of the school administrators, parents, and guidance counselor in helping the students choose the suitable career for them is vital [3]. Hence, the National Career Assessment Examination (NCAE) is also administered to junior secondary students as one way of assessing the aptitude and potential of students to pursue a career [4]. But this is not enough due to numerous factors such as interest in the course [5], situational factors, parental influence, school attended, gender, prestige attachment, and passion [6][7]. As well as the ability of the learners to identify their preferred career choice, family, and teachers have significant role in influencing the student [8] and the environmental factors like counselor or other members of the family aside from parents, teachers, and friends, opportunity, their own personality traits [9], and capacity. One way of addressing these issues is by using a recommender system that would suggest an appropriate career [10] to K to12 students [11] which helps them in their decision [12] so that they can have better studying plans[13] and would be able to assist career coordinators or counselors that give significant role in counseling students [14].

There are three common filtering techniques in most recommender systems such as : content-based, collaborative and hybrid approach [15] where different algorithmic approaches are employed like k-means in a collaborative filtering (CF) for advising students on what course to enroll based on their general point average or GPA [16] and conventional neural network in a content-based filtering methods in recommending learning resources to students [17]. A combination of content-based and collaborative filtering to become a hybrid recommendation system was also used to predict suitable colleges that match the students' profiles using rules algorithms and to advised students on which track to enter [18].

Rules usually represent general knowledge [19] just like knowledge-based recommendation system in a hybrid approach which aims to assist students to select suitable courses based on their skills was used in an inference engine [20] to recommend based on user's preference [21] using user models as implicit and explicit information for personalized learning [22]. This allows the user to achieve the desired goal or interest. Additionally, association rules were also used to recommend courses to students including an enhanced apriori algorithm based on their grades [23] and to select the best major for them [24].

Nonetheless, proposing a recommendation system to choose a career path based on grades or school performance is not enough, thus other relevant factors are also needed [25] to be considered in developing career recommendation system [26]. Moreover, career uncertainty is an issue that students 
face in the present [27] since they are also often uncertain about their choice of future career [28] even if they are already enrolled in their current career track [29]. These are the reasons why this issue must be addressed [30]. The problem, however, is that uncertainty is still unresolved in a rule-based recommender system [31].

To address this issue, a soft computing approach must be used to handle uncertainty and fuzziness in students' decision. One such approach is Fuzzy Logic or FL [32] which was introduced by Lotfi Zadeh in 1965. Since it is also one of computational intelligence techniques that resolves vagueness in item features and user's behavior [33], profile like skills and experience[34], even ambiguities and uncertainties in recommendation [35] as well as factors [36] affecting the career decisions of students will be addressed.

\subsection{Objectives of the Study}

In reference to the stated problem above, this study aims to:

1. determine the significant factors as attributes of students that influence their career decisions using feature selection technique;

2. assess the accuracy of the fuzzy logic model in predicting career track;

3. validate the result with the desired preference of the students and the actual recommendation of the system; and

4. determine the level of acceptability of the career track determination using fuzzy logic in an educational setting.

\section{LITERATURE REVIEW}

\subsection{Fuzzy Logic}

Fuzzy logic (FL) use the notion of degrees of truth, that values may range between 0 to 1 . Linguistic variables were also used to manage specific membership functions. FL has been developed to manage vagueness and uncertainty in a reasoning process in an intelligent system such as an expert system, knowledge-based system, and logic control system [37][38]. These features of FL enables it to become widely used in recommendation system so as to provide personalized online services by automatically suggesting products/ services to customers with high accuracy even if there is a challenge in existing uncertainties within the customer and product data [39][40]. It can also solve high sparsity problems of user rating matrix and be more efficient when the matrix is more sparse [41].

In education, FL was used in expert systems to evaluate students' academic performance [42], to analyze students' lifestyle [43], providing interactive recommendations with interactive and meaningful engagement in innovative e-learning [44], and to assist teachers, examiners and evaluators in managing uncertainties in the decision making process in evaluating the students [45].

\subsection{Feature Selection}

Feature selection techniques are effectively used together with many classification techniques in an educational setting like predicting a student performance model because the learning efficiency and performance accuracy are enhanced especially that the complexity of the learned results reduced [46]. Consequently, it gives several benefits such as the removal of irrelevant features [47] and with these limited number of features, still, promising results were achieved [48]. In addition, by using feature selection in identifying significant factors as well as the students' characteristics [49] that influence the studying performance of students [50] and in using them in a warning system, is very helpful to the learners as well as to the teachers in evaluating academic performance for improvement [51] since this is the primary goal of all educational organizations [52].

As stated earlier, the senior high school secondary students are exposed in numerous influential factors as attributes, and in dealing with this diverse and vast amount of data, issues in computational time and complexity must also be considered to produce a quality prediction model in classification [53] and to address this, the application of feature selection is needed [54] since it is used in pre-processing step of data by selecting appropriate subset of features as relevant student attributes before they will be used in developing the fuzzy logic model. There are three feature selection methods: filter, wrapper, and embedded method. In this study, filter methods are used because they generally function in pre-processing as features are selected based on the characteristic of the data [55]. Furthermore, these methods can easily cope with classification tasks in feature spaces of large dimensionality[56].

\section{METHODOLOGY}

\subsection{Data Collection}

The datasets were gathered from the Grade 11 and 12 senior high school students of the two schools division in the province of Isabela with prior approval from the schools' division superintendent and academic heads of each school through a questionnaire that identified the demographic data and other relevant factors needed with the following attributes as shown table 1 .

Table 1: Pre-determined attributes from the gathered student data

\begin{tabular}{|c|c|c|c|}
\hline Attribute Name & Description & Attribute Name & Description \\
\hline Track & $\begin{array}{l}\text { Senior High } \\
\text { School Tracks }\end{array}$ & Interest & $\begin{array}{l}\text { Interest of the } \\
\text { students with the } \\
\text { current track }\end{array}$ \\
\hline Strands & $\begin{array}{l}\text { Current strands } \\
\text { enrolled }\end{array}$ & Parent_income & $\begin{array}{l}\text { Parent's monthly } \\
\text { income }\end{array}$ \\
\hline Age & Age of the student & Parents_influence & Influence of Parents \\
\hline Gender & Student's gender & Relatives & $\begin{array}{l}\text { Influence of } \\
\text { Relatives }\end{array}$ \\
\hline $\begin{array}{l}\text { Father_- } \\
\text { Occupation }\end{array}$ & $\begin{array}{l}\text { Father's } \\
\text { Occupation }\end{array}$ & Peers & Peer Influence \\
\hline $\begin{array}{l}\text { Father_educ_ } \\
\text { attainment }\end{array}$ & Father's Education & $\begin{array}{l}\text { Socio_economic_ } \\
\text { status }\end{array}$ & $\begin{array}{l}\text { Socio Economic } \\
\text { status of the family }\end{array}$ \\
\hline $\begin{array}{l}\text { Mother_- } \\
\text { Occupation }\end{array}$ & $\begin{array}{l}\text { Mother's } \\
\text { Occupation }\end{array}$ & Proximity & Proximity of School \\
\hline $\begin{array}{l}\text { Mother_educ_ } \\
\text { attainment }\end{array}$ & $\begin{array}{l}\text { Mother's } \\
\text { Education }\end{array}$ & Job_opportunities & Prestige of career \\
\hline Final_Grade & $\begin{array}{l}\text { Cumulative Grade } \\
\text { Point average }\end{array}$ & & \\
\hline
\end{tabular}

The pre-determined attributes as shown in table 1 with description were filtered using feature selection filtering techniques to determine the best attribute which further used in developing the fuzzy logic model. 


\subsection{Pre-processing of Data}

The dataset from 716 students was divided in three as 60 percent of the population was considered as the train set composed of 429 students, and the remaining 40 percent has been divided to validation set which is 144 , and 143 for the test set, respectively. All unnecessary spaces are removed and wrong input texts were edited before they were converted to a CSV file. Weka 3.8.0 was used for feature selection using the Correlation-based, InfoGain, and ReliefF methods.

\subsection{Developing the Fuzzy Logic Model}

In designing a fuzzy inference system (FIS), a simple diagram was shown in figure 1 which shows the flow of operation in the system.

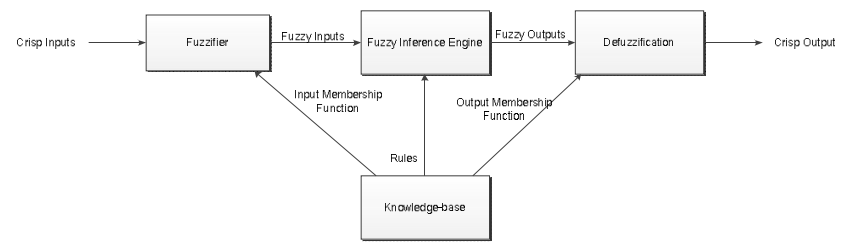

Figure 1: Fuzzy inference system diagram

The crisp input will enter a fuzzifier and undergo a fuzzification process which transforms input data to become fuzzy inputs which will then serve as inputs together with the rules from knowledge-base are evaluated in a fuzzy inference engine to become as fuzzy outputs. These outputs will be aggregated and undergo defuzzification to give the result as shown in figure 2.

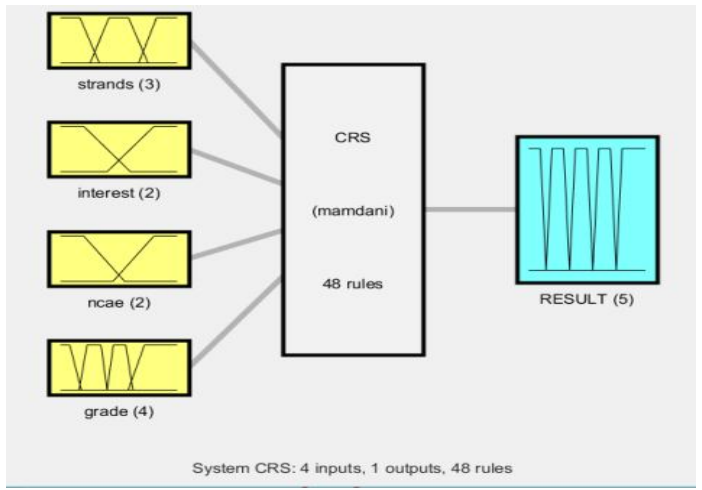

Figure 2. Fuzzy inference system diagram

Figure 2 shows the fuzzy inference system or FIS of the prototype career track recommender system using the Matlab's Fuzzy Logic Toolbox version r2017a. It has four inputs and one output as variable and the inference engine using Mamdani type with 48 rules.

\subsubsection{Fuzzification}

Since fuzzy rules are in linguistic forms, the fuzzy input and output variables must assign to the corresponding linguistic values as shown in table 2 .
Table 2: Fuzzy input and output variables and equivalent linguistic values

\begin{tabular}{ll}
\hline Fuzzy Variable & Linguistic Values \\
\hline Track/strand & $\mathrm{AD}, \mathrm{TVL}, \mathrm{AC}$ \\
Interest & $\mathrm{CY}, \mathrm{CN}$ \\
NCAE & $\mathrm{CY}, \mathrm{CN}$ \\
Final Grade & FS, S, VS, O \\
Result & Very Low, Low, Average, \\
& High, Very High \\
\hline
\end{tabular}

Table 2 indicates the fuzzy input and output variables with equivalent linguistic values which entered in the fuzzy inference system in developing a fuzzy model. The type of the membership function depends on the actual applications and in this study a trapezoidal curve was used which depends on four parameters as shown in equation 1 .

$$
f(x ; a, b, c, d)=\left\{\begin{array}{cl}
\frac{x^{0}-a}{b-a} & \text { for } \mathrm{x}<\mathrm{a} \\
\frac{1}{1-x} & \text { for } \mathrm{b} \leq x<b \\
\frac{d-c}{d-c} & \text { for } \mathrm{c} \leq x<d \\
0 & \text { for } \mathrm{d} \leq x
\end{array}\right.
$$

Each membership functions for the FIS variables are constructed using trapezoidal membership function or trapmf.

\subsubsection{Fuzzy Rules}

Before constructing the fuzzy rules, academic advisors and expert in the field were interviewed and asked which serve as the basis to build the fuzzy model as shown in the next figure.

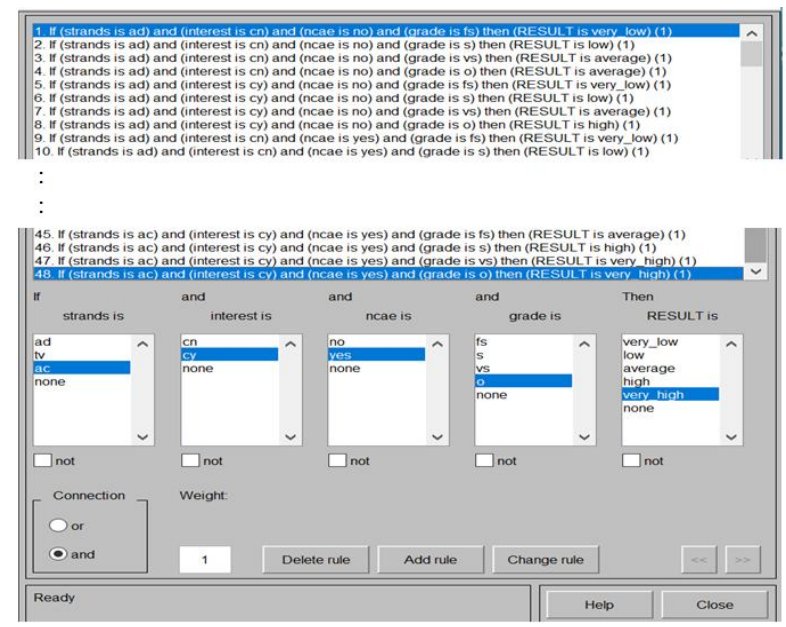

Figure 3: Fuzzy rules for creating fuzzy logic model

The rule editor in the fuzzy inference system which was used in creating fuzzy rules in linguistic form to produce a fuzzy logic model as shown in figure 3 has four input variables as the if-part or antecedent and one output variable as the then-part or consequent of the conditional statement.

\subsubsection{Defuzzification}

The commonly used deffuzification method is center of gravity (COG) which the output corresponds to the center 
of gravity of the surface of membership function characterizing the fuzzy set that resulting from the aggregation of the implication results of the career track recommender system (CRS) fuzzy inference system in Mamdani type where the andMethod is "min" using "centroid" with the given equation below.

$$
D=\frac{\sum_{x}^{b}=a y_{i} x_{i}}{\sum_{x}^{b}=a y_{i}}
$$

Whereas, D determines the center of gravity (centroid) of $y_{i}$ of the membership degree of $x$ and $a$ and $b$ as interval values which use the value as the output of the FIS.

\subsection{Evaluation Metrics}

The root-mean-square error (RMSE) and mean absolute error (MAE) are used to measure the performance of the developed fuzzy model as shown in equation 3 and 4 and normalized discounted cumulative gain for the rank of the students rating with the given recommendation in equation 5, respectively.

$$
\begin{gathered}
R M S E=\sqrt{\frac{1}{N} \sum_{i=1}^{n} e_{i}^{2}} \\
M A E=\frac{1}{N} \sum_{i=1}^{n} e_{i} \\
\operatorname{NDCG}_{D}\left(f, S_{n}\right)=\frac{\operatorname{DCG}_{D}\left(f, S_{n}\right)}{\operatorname{IDCG}_{D}\left(S_{n}\right)} .
\end{gathered}
$$

In determining the level of acceptability of the recommender system from the users, a Likert's scale must be used as presented to the next table.

Table 3: Likert's scale and descriptive interpretation for the weighted mean of the level of acceptability of the recommender system

\begin{aligned} & \hline \multicolumn{1}{c}{ Scale } \multicolumn{1}{c}{ Interpretation } \\ & \hline $4.21-5.00$ Strongly Agree \\ & $3.41-4.20$ Agree \\ & $2.61-3.40$ Fairly Agree \\ & $1.81-2.60$ Disagree \\ & $1.00-1.80$ Strongly Disagree \\ & \hline\end{aligned}

Table 3 shows the Likert's scale used for the weighted mean with equivalent descriptive interpretation in determining the level of acceptability of the recommendation system in terms of usability, maintainability, and portability as adopted from [57] based on the international software testing standard, ISO/IEC 9126.

\section{EXPERIMENTAL RESULTS}

\subsection{Significant attributes of students}

The selected best attributes using filtering techniques of feature selection were: National Career Assessment
Examination (NCAE) result, strands, final grade, and interest of the students which these attributes are used as crisp inputs in the fuzzy inference system as shown in the table below.

Table 4: Selected attributes using Feature Selection filtering

\begin{tabular}{cccc}
\multicolumn{3}{c}{ methods } \\
\hline Rank & Correlation & Information Gain & ReliefF \\
\hline 1 & Track & Track & Track \\
2 & Interest & NCAE & Interest \\
3 & Final Grade & Interest & Final Grade \\
4 & NCAE & Final Grade & NCAE \\
\hline
\end{tabular}

Table 4 shows the result of the feature selection filtering techniques performed in selecting the four best attributes based on their rank from the three filtering techniques used that will serve as important input variables in developing the fuzzy model.

\subsection{Accuracy of the fuzzy logic model}

It is necessary to evaluate the fuzzy inference system using evalfis function for a given set of inputs as shown in figure 4 .

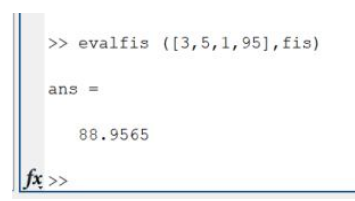

Figure 4: Sample result of evaluation of the fuzzy inference system

The fuzzy inference engine was then evaluated using "evalfis" and the result was shown in figure 4. Here, the four input data are 3 as strands/track input, 5 for interest, 1 for NCAE and 95 as grade which the result as ans is equal to 88.9565. This indicates that the students have $88.95 \%$ chance of pursuing their chosen career as related to their current track.

From the 60 percent of the total population considered as the train set, 20 percent for the validation set, and another 20 percent for the test set, the computed MAE and RMSE were drawn as presented in Table 5.

Table 5: Performance evaluation of the developed model in

\begin{tabular}{ccc} 
& the dataset & \\
\hline Dataset & MAE & RMSE \\
\hline Training Set & 2.013 & 4.126 \\
Validation Set & .8765 & 3.767 \\
Test Set & .1764 & 2.893 \\
\hline
\end{tabular}

Table 5 shows that RMSE as a measure of predictive accuracy decreases the value from the training set to the test set. This means that a smaller value indicates less difference between the estimated and actual values. Additionally, with the decrease of the RMSE, the predictive accuracy of the model improves. 


\subsection{Validation of the actual recommendation}

Aside from evaluating the accuracy of the predictive model, the result of the recommendation was also tested based on the response of the students as shown in the next table.

Table 6: Summary of computed normalized discounted cumulative gain for the result of the recommendation to students

\begin{tabular}{cccc}
\hline $\begin{array}{c}\text { Number } \\
\text { of } \\
\text { Students }\end{array}$ & $\begin{array}{c}\text { Cumulative } \\
\text { Gain }\end{array}$ & $\begin{array}{c}\text { Discounted } \\
\text { Cumulative } \\
\text { Gain (DCG) }\end{array}$ & $\begin{array}{c}\text { Normalized Discounted } \\
\text { Cumulative Gain } \\
\text { (nDCG) }\end{array}$ \\
\hline 50 & 210 & 57.837 & 0.948 \\
\hline
\end{tabular}

Table 6 shows the summary of the computed normalized discounted cumulative gain which is 0.948 to measure the result of the recommendation based on the feedback of the students whether the given recommendation was acceptable or not.

Furthermore, from the predictable range of 0.0 to 1.0 , which 0.0 the system performs terribly, the computed result indicates that the career recommendation system returns the best possible answers or recommendation to students.

\subsection{Level of Acceptability}

The simulation of the recommendation result was tested and showed to the guidance counselor and students as shown in the following figures.

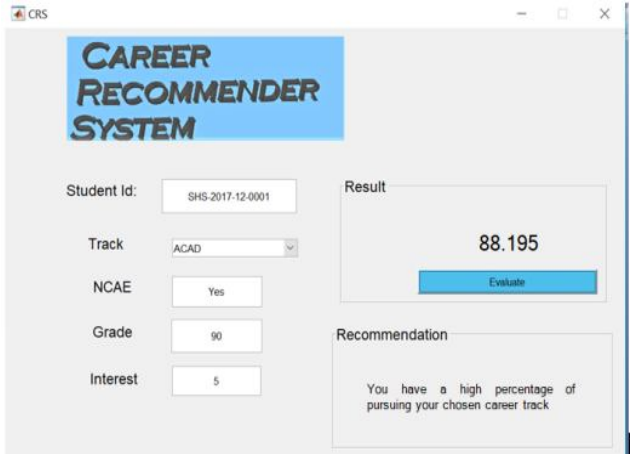

Figure 5: Graphical user interface of the CRS

Figure 5 is a sample GUI of the CRS showing the recommendation to a student which indicates a high opportunity of pursuing the chosen career track based on the given input data as factors. Another simulation was done with a different set of inputs as shown in figure 6 .

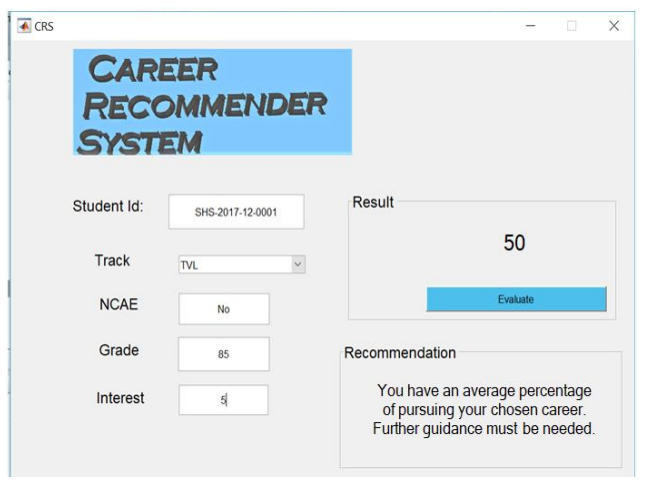

Figure 6: Sample GUI of CRS
Figure 6 is another sample GUI of the CRS showing the recommendation to a student which indicates an average chance of pursuing the chosen career track based on the given input data as factors and that additional or adequate guidance is needed to deliver to them.

The black box testing for the prototype of the recommender system was also performed and the rate of the end-users on the usability of the system is presented in table 7 .

Table 7: Weighted mean and descriptive interpretation of end-users on usability of the system

\begin{tabular}{lcc}
\hline Criteria & Mean & $\begin{array}{c}\text { Descriptive } \\
\text { Interpretation }\end{array}$ \\
\hline $\begin{array}{l}\text { 1. The system is easy to learn and use } \\
\text { by novice computer users. }\end{array}$ & 4.8 & $\begin{array}{c}\text { Strongly } \\
\text { Agree }\end{array}$ \\
$\begin{array}{l}\text { 2. The system has icons/ symbols for } \\
\text { easy recognition and navigation to } \\
\text { different forms. }\end{array}$ & 4.1 & Agree \\
$\begin{array}{l}\text { 3. The information on the system } \\
\text { screen is well-organized and clear. }\end{array}$ & 4.7 & $\begin{array}{c}\text { Strongly } \\
\text { Agree }\end{array}$ \\
$\begin{array}{l}\text { 4. The graphical user interface of the } \\
\text { system is pleasant user-friendly. }\end{array}$ & 4.6 & $\begin{array}{c}\text { Strongly } \\
\text { Agree }\end{array}$ \\
\hline \begin{tabular}{l} 
Weighted Mean \\
\hline
\end{tabular} & 4.55 & $\begin{array}{c}\text { Strongly } \\
\text { Agree }\end{array}$ \\
\hline
\end{tabular}

Table 7 shows the mean and descriptive interpretation of end-users' rating on the usability of the system. The respondents strongly agreed on most of the criteria and just agreed in the second item. The data further reveals that the majority strongly agreed on the usability of the system with a weighted mean of 4.55 .

The expertise of IT experts was also considered by evaluating the prototype as it undergoes white box testing on its maintainability which shown in table 8 .

Table 8: Weighted mean and descriptive interpretation of IT Experts on maintainability of the system

\begin{tabular}{lcc}
\hline Criteria & Mean & $\begin{array}{c}\text { Descriptive } \\
\text { Interpretation }\end{array}$ \\
\hline $\begin{array}{l}\text { 1. The system code is composed of } \\
\text { different functions that are performs }\end{array}$ & 4.51 & Strongly Agree \\
$\begin{array}{l}\text { well in the low level modules. } \\
\begin{array}{l}\text { 2. The code used the commonly } \\
\text { used basic techniques and }\end{array}\end{array}$ & 4.73 & Strongly Agree \\
structures. & & \\
$\begin{array}{l}\text { 3. The system has high order } \\
\text { programming codes. }\end{array}$ & 4.81 & Strongly Agree \\
$\begin{array}{l}\text { 4. The root cause of errors and bugs } \\
\text { in the system code can easily be } \\
\text { determined. }\end{array}$ & 4.66 & Strongly Agree \\
\hline Weighted Mean & 4.68 & Strongly Agree \\
\hline
\end{tabular}

Table 8 shows the weighted mean and descriptive interpretation of IT experts' rating on maintainability of the system where the majority of the respondents strongly agreed on the given set of criteria. Furthermore, they all strongly agreed on the maintainability of the system.

Aside from the maintainability of the prototype, the portability was also tested by the same set of respondents which are the IT experts as shown in the next table. 
Table 9: Weighted mean and descriptive interpretation of IT Experts on portability of the system

\begin{tabular}{|c|c|c|}
\hline Criteria & $\begin{array}{l}\text { Weighted } \\
\text { Mean }\end{array}$ & $\begin{array}{c}\text { Descriptive } \\
\text { Interpretation }\end{array}$ \\
\hline $\begin{array}{l}\text { 1. The system can easily } \\
\text { be installed by any IT } \\
\text { Professional on site. }\end{array}$ & 4.81 & Strongly Agree \\
\hline $\begin{array}{l}\text { 2. The data in the } \\
\text { database are accurate } \\
\text { and consistent. }\end{array}$ & 4.45 & Strongly Agree \\
\hline $\begin{array}{l}\text { 3. The system can be } \\
\text { installed and used in } \\
\text { different operating } \\
\text { environments. }\end{array}$ & 4.74 & Strongly Agree \\
\hline $\begin{array}{l}\text { 4. The system is } \\
\text { compliant to the standard } \\
\text { software testing } \\
\text { requirements. }\end{array}$ & 4.88 & Strongly Agree \\
\hline Weighted Mean & 4.72 & Strongly Agree \\
\hline
\end{tabular}

Table 9 shows the weighted mean and descriptive interpretation of IT experts' rating on portability of the system where the majority of the respondents strongly agreed on the given set of criteria. Furthermore, they all strongly agreed on the portability of the system

\section{CONCLUSION AND FUTURE WORKS}

In this study, a fuzzy-based recommender system is indicated to be beneficial for senior high school students to address the uncertainties in their career decision. However, since numerous factors are considered, feature selection techniques are used to remove irrelevant student attributes and resulted to have only four significant attributes so that the fuzzy inference model will generate reasonable results. With that, obtained results show improvement in the accuracy and efficiency of the fuzzy logic model.

Different evaluation metrics were also used such as MAE and RMSE to measure the accuracy of the model and based on the result, the predictive accuracy is high since the computed values were near to zero. Results indicated that the students highly accepted the given recommendation to them given the high performance with less difference from the actual to the predicted value as regard to the $\mathrm{nDCG}$ result.

It is also found out that the career track determination using fuzzy logic is timely and will be useful for helping the senior high school students under the $\mathrm{K}$ to 12 program due to it is highly acceptable to the end-users as they strongly agreed to its usability, maintainability, and portability.

For improvement and further work, the proposed system needs to be evaluated for more test sets with the different set of criteria since the student attributes selected are liable to change as significant factors from real data can also change.

Moreover, an online version of career track recommender system must be developed and implemented in the future so that students can access it anytime and anywhere. For more valid result, an enhancement is needed whether the recommendation is will also be acceptable to new set of students in the future.
It is also highly recommended that this career track recommender system should be fully implemented to serve its purpose to students, school administrators, and other stakeholders.

\section{ACKNOWLEDGEMENT}

We would like to express our sincerest gratitude to the two former Schools Division Superintendent of Isabela, Mr. Jessie L. Amin and Dr. Gilbert Narag Tong of Cauayan City Schools Division, together with the former principal of Cauayan City National High School, Mr. John R. Mina and other school principals for allowing the conduct of this study in their respective schools.

\section{REFERENCES}

[1] SEAMEO and INNOTECH, K to 12 Toolkit. 2012.

[2] DepED, "Department of Education Guidebook: An Introductory Guide to Senior High School," 2015.

[3] N. T. Pascual, "Factors Affecting High School Students ' Career Preference: A Basis for Career Planning Program," Int. J. Sci. Basic Appl. Res., vol. 16, no. 1, pp. 1-14, 2014.

[4] E. Escudero, HB02204_NCAE bill. 2013, pp. 1-7.

[5] J. M. Laguador, "Examination of Influence and Intention towards Lyceum of the Philippines University and Career Choice of General Engineering Students," Int. J. Manag. Sci., vol. 3, no. 11, pp. 847-855, 2014.

[6] S. U. Esther and A. A. Ayuk, "Templates That Determines the Choice of Course Selection in the University: A Case Study of University of Calabar Departmentof Sociology ," J. Emerg. Trends Educ. Res. Policy Stud., vol. 4, no. 2, pp. 246-251, 2013.

[7] M. D. Eremie, "Comparative Analysis of Factors Influencing Career Choices among Senior Secondary School Students in Rivers State, Nigeria," Arab. J. Bus. Manag. Rev., vol. 4, no. 4, pp. 20-25, 2014. https://doi.org/10.12816/0019060

[8] A. Shumba and M. Naong, "Factors Influencing Students ' Career Choice and Aspirations in South Africa," J. Soc. Sci., vol. 33, no. 2, pp. 169-178, 2012. https://doi.org/10.1080/09718923.2012.11893096

[9] S. O. Olamide and S. Oluwaseun, "The Factors Determining the Choice of Career Among Secondary," Int. J. Engineeering Sci., vol. 2, no. 6, pp. 33-44, 2013.

[10] D. Upendran, S. Chatterjee, S. Sindhumol, and K. Bijlani, "Application of Predictive Analytics in Intelligent Course Recommendation," Procedia Procedia Comput. Sci., vol. 93, pp. 917-923, 2016. https://doi.org/10.1016/j.procs.2016.07.267

[11] D. Grewal and K. Kaur, "Developing an Intelligent Recommendation System for Course Selection by Students for Graduate Courses," Businee Econ. J., vol. 7, no. 2, pp. 1-9, 2016.

https://doi.org/10.4172/2151-6219.1000209

[12] H. Bydžovská, "Course Enrollment Recommender System," in Proceedings of the 9th International 
Conference on Educational Data Mining, 2013, no. x, pp. 312-317.

[13] Huynh-Ly, Thanh-Nhan, H.-H. Nguyen, and T.-N. Nguyen, "Methods for building course recommendation systems," pp. 163-168, 2016. https://doi.org/10.1109/KSE.2016.7758047

[14] Y. Lee and J. Cho, "An Intelligent Course Recommendation System," Smart Comput. Rev., vol. 1, no. 1, pp. 69-84, 2011.

https://doi.org/10.6029/smartcr.2011.01.006

[15] F. O. Isinkaye, Y. O. Folajimi, and B. A. Ojokoh, "Recommendation systems : Principles, methods and evaluation," Egypt. Informatics J., vol. 16, pp. 261-273, 2015.

[16] K. Ganeshan, "An Intelligent Student Advising System Using Collaborative Filtering," 2015.

[17] J. Shu, X. Shen, H. Liu, B. Yi, and Z. Zhang, "A content-based recommendation algorithm for learning resources," Multimed. Syst., vol. 0, no. 0, p. 0, 2017.

[18] A. H. M. Ragab, A. F. S. Mashat, and A. M. Khedra, "HRSPCA: Hybrid Recommender System for Predicting College Admission," in 12th International Conference on Intelligent Systems Design and Applications (ISDA), 2012, pp. 107-113.

https://doi.org/10.1109/ISDA.2012.6416521

[19] J. Prentzas and I. Hatzilygeroudis, "Categorizing Approaches Combining Rule-Based and Case- Based Reasoning Categorizing Approaches Combining Rule-Based and Case- Based Reasoning," Expert Syst., vol. 24, no. 2, pp. 97-122, 2007. https://doi.org/10.1111/j.1468-0394.2007.00423.x

[20] M. Pallavi, P. Vaisakh, and N. P. Reshna, "Implementation of RETE Algorithm Using Course Finder System," 2014.

[21] R. Burke, "Hybrid Recommender Systems : Survey and Experiments $\dagger, "$ pp. 1-29, 2010.

[22] A. Zaldivar and D. Burgos, "Meta-Mender: A meta-rule based recommendation system for educational applications," Procedia Comput. Sci., vol. 1, no. 2, pp. 2877-2882, 2010.

[23] P. Bhandari, C. Withana, A. Alsadoon, and A. Elchouemi, "Enhanced Apriori Algorithm Model in Course Suggestion System," 2015.

[24] A. Alshareef, S. Ahmida, and M. Alweshah, "Mining Survey Data on University Students to Determine Trends in the Selection of Majors," in Science and Information Conference, 2015, pp. 586-590.

https://doi.org/10.1109/SAI.2015.7237202

[25] G. Meryem, K. Douzi, and S. Chantit, "Toward an E-orientation Plateform Using hybrid recommendation systems," 2016.

[26] M. L. Waghmode and P. P. Jamsandekar, "A Study of Expert System for Career Selection: Literature Review," Int. J. Adv. Res. Comput. Sci. Softw. Eng., vol. 5, no. 9, pp. 779-785, 2015.

[27] H. Cariño-Mattison, "Sigurado Ka Na Ba ? Exploring Career Uncertainty in Filipino College Students," Philipp. Soc. Sci. Rev., vol. 1, no. 1, pp. 157-195, 2015.

[28] H. Botha and K. Mostert, "Significant predictors associated with the career uncertainty of university students," no. January 2013, 2015.

[29] B. Schadl, S. Dr. Sheppard, and H. Dr. Chen, "Career Certainty: Differences Between Career Certain and Uncertain Engi- neering Students Career Certainty: Differences between career certain and uncertain engineering students," Am. Soc. Eng. Educ., vol. 1, pp. 1-21, 2017.

[30] M. Sollitto, J. Brott, C. Cole, E. Gil, and H. Selim, "Students' uncertainty management in the college classroom Students ' uncertainty management in the college classroom," Commun. Educ., pp. 1-15, 2017. https://doi.org/10.1080/03634523.2017.1372586

[31] V. Moret-Bonillo, I. Fernandez-Varela, and D. Alvarez-Estevez, "Uncertainty in Quantum Rule-Based Systems," pp. 1-20, 2018.

[32] S. M. Darwish, M. M. Madbouly, and E. Abd-el Reheem, "Contribution to Collaborative Filtering Based on Soft Computing to Enhance Recommender System for e-Commerce," Int. J. e-Education, e-Business, e-Management e-Learning, vol. 4, no. 4, pp. 257-270, 2014.

https://doi.org/10.7763/IJEEEE.2014.V4.341

[33] A. Jain and C. Gupta, "Fuzzy Logic in Recommender Systems Fuzzy Logic in Recommender Systems," in Studies in Computational Intelligence, no. January, Springer International Publishing AG 2018, 2018, pp. 255-273.

[34] M. June, E. Journal, C. C. Escolar-jimenez, K. Matsuzaki, and R. C. Gustilo, "Intelligent Shortlisting Process for Job Applicants Using Fuzzy Logic-Based Profiling," Int. J. Adv. Trends Comput. Sci. Eng., vol. 8, no. 3, pp. 567-572, 2019. https://doi.org/10.30534/ijatcse/2019/36832019

[35] A. Abbas, L. Zhang, and S. U. Khan, "A survey on context-aware recommender systems based," Computing, vol. 97, no. 7, pp. 667-690, 2015. https://doi.org/10.1007/s00607-015-0448-7

[36] S. Rajaprakash, R. Ponnusamy, R. Jaichandran, K. Karthik, and K. Somasundaram, "Determining the School Students Stress Factors Using Fuzzy Analytical Hierarchy Process," Int. J. Pure Appl. Math., vol. 118, no. 5, pp. 889-900, 2018.

[37] Y. Yu and E. R. Fowler, "Rule based fuzzy logic inferencing," in Proceedings of IEEE International Conference on Systems, Man and Cybernetics, 1994, pp. $465-470$.

[38] V. M. D. Manalo, E. R. Arboleda, J. L. D. Jr, and R. M. Dellosa, "Differentiation Among Lettuce ( L . Sativa ) Seed Varieties Grown In Gourmet Farms, Silang Cavite, Philippines Using Image Processing With Fuzzy Logic And Knn As Classifiers," Int. J. Sci. Technol. Res., vol. 8, no. 10, pp. 8-11, 2019.

[39] Z. Zhang, H. Lin, K. Liu, D. Wu, G. Zhang, and J. Lu, "A hybrid fuzzy-based personalized recommender system for telecom products / services," Inf. Sci. (Ny)., vol. 235, pp. 117-129, 2013.

[40] P. M. Soni and P. Varghese, "A Fuzzy based Data mining Approach for the Loan Credibility Prediction System in Co-operative Banking Sector," Int. J. Adv. 
Trends Comput. Sci. Eng., vol. 8, no. June, pp. 815-820, 2019.

https://doi.org/10.30534/ijatcse/2019/74832019

[41] P. Fang and S. Zheng, "A Research on Fuzzy Formal Concept Analysis Based Collaborative Filtering Recommendation System," 2009.

[42] P. Meenakshi \& Nagar, "Fuzzy Logic Based Expert System for Students '," pp. 4-9, 2015.

[43] S. Ghosh, A. S. Boob, N. Nikhil, N. R. Vysyaraju, and A. Kumar, "A Fuzzy Logic System to Analyze a Student' s Lifestyle," 2016.

[44] J. Antony, S. Ramakrishnan, M. T. Joy, and R. Thottupuram, "2012 IEEE Fourth International Conference on Technology for Education SMS based E-Assessments enabling better Student Engagement, Evaluation and Recommendation Services in E-Learning making use of Fuzzy Rules and Course Ontologies," 2012. https://doi.org/10.1109/T4E.2012.9

[45] M. N. A. Khalid, U. K. Yusof, and L. G. Xiang, "Model Student Selection Using Fuzzy Logic Reasoning Approach," 2016.

[46] C. Anuradha and T. Velmurugan, "FEATURE SELECTION TECHNIQUES TO ANALYSE STUDENT ACADAMIC PERFORMANCE USING NAÏVE BAYES STUDENT ACADAMIC PERFORMANCE USING NAÏVE," Conf. Proc. Small Mediu. Bus., vol. January 19, no. April, pp. 345-350, 2016.

[47] R. S. Regha and R. U. Rani, "Optimization Feature Selection for classifying student in Educational Data Mining," Int. J. Innov. Eng. Technol., vol. 7, no. 4, pp. 490-496, 2016.

[48] H. Almayan and W. Al Mayyan, "Improving Accuracy of Students ' Final Grade Prediction Model Using PSO," Conf. Proceeding 6th Int. Conf. Inf. Commun. Manag., vol. 16, pp. 35-39, 2016. https://doi.org/10.1109/INFOCOMAN.2016.7784211

[49] K. Maharani, T. B. Adji, N. A. Setiawan, and I. Hidayah, "Comparison Analysis of Data Mining Methodology and Student Performance Improvement Influence Factors in Small Data Set," Conf. Proceeding Int. Conf. Sci. Inf. Technol., vol. 15, pp. 169-174, 2015.

[50] R. R. Saedudin and E. Sutoyo, "Attribute Selection on Student Performance Dataset Using Maximum Dependency Attribute," Confererence Proceeding 5th Int. Conf. Electr. Electron. Inf. Eng., vol. 17, pp. 176-179, 2017.

[51] V. Shanmugarajeshwari and R. Lawrence, "Analysis of Students , Performance Evaluation using Classification Techniques," 2016. https://doi.org/10.1109/ICCTIDE.2016.7725375

[52] M. Zaffar, S. Iskander, and M. A. Hashmani, "A Study of Feature Selection Algorithms for Predicting Students Academic Performance," Int. J. Adv. Comput. Sci. Appl., vol. 9, no. 5, pp. 541-549, 2018. https://doi.org/10.14569/IJACSA.2018.090569

[53] A. M. Shahiri, W. Husain, N. Aini, and A. Rashid, "A Proposed Framework on Hybrid Feature Selection
Techniques for Handling High Dimensional Educational Data," AIP Conf. Proc. 1891, vol. $020130,2017$.

[54] A. Acharya and D. Sinha, "Application of Feature Selection Methods in Educational Data Mining," Int. J. Comput. Appl., vol. 103, no. 2, pp. 34-38, 2014.

[55] S. Wang, J. Tang, H. Liu, and E. Lansing, "Feature Selection," Encycl. Mach. Learn. Data Min., vol. 101-1, pp. 1-9, 2016.

[56] M. Haindl, P. Somol, and D. Ververidis, "Feature Selection Based on Mutual Correlation," in Progress in Pattern Recognition, Image Analysis and Applications: 11th Iberoamerican Congress in Pattern Recognition, 2006, pp. 569-577. https://doi.org/10.1007/11892755_59

[57] C. D.- Omorog, "Development of Graphical User Interface Student Electoral System," Asia Pacific J. Multidiscip. Res., vol. 4, no. 3, pp. 137-145, 2016. 